\title{
Editorial
}

\section{Children in the Legal System}

The focus of this special issue of the Australian Educational and Developmental Psychologist is children in the legal system. The past 20 years have seen significant changes in the legal status of children in Australia and other Western societies. These legal changes reflect the changing values in society and are an explicit recognition by societies of the importance of protecting the young not only from physical harm but also from social, sexual, and emotional harm. Perhaps the clearest and most influential expression of this concern for children is found in the United Nations Convention on the Rights of the Child.

The concern for the physical, social, sexual, and emotional well-being of children has resulted in amendments in Australian legislation in a wide variety of Legislative Acts in the different jurisdictions, for example, Children and Young Persons Acts, Child Protection Acts, Adoption Acts, Family Law Act, Evidence Acts, and Crimes Acts/Criminal Codes. The fundamental principle articulated in these amendments is the best interests of the child. Evidence Acts have been amended to remove barriers that prevented children testifying. Procedures have been set in place to make court procedures more user-friendly for children. However, not all the changes or contemplated legislative changes are child-friendly. Amendments to Acts are being introduced in many jurisdictions reducing the age at which a child is criminally responsible and can be tried in a court of law.

The domains of law that have the most impact on children are child protection Acts, the Family Law Act, and laws to do with criminal offences. The six articles contained in this volume explore aspects of the child as a victim and the child as an offender. The first article in this volume, by Don Thomson \& Sue Molloy, examines the principle of best interest of the child. Although this principle is particularly pertinent to matters of child protection and family laws, it is an overarching principle relevant to all aspects of children in the legal system. The second article, by Clare Wilson, is concerned with the age of criminal responsibility at which children should be held accountable to the criminal justice system. This article is timely because recent well-publicised cases of young children aged 10, 11, 12 , and 13 abducting and killing young children has generated enormous public debate. The third paper, by Martine Powell \& Don Thomson, 
examines ways to facilitate accurate recall by children who are victims of repeated abuse and, thus, to increase the likelihood of successful prosecution of the perpetrators of this abuse.

The fourth article, by Tony Thompson, is about juvenile offenders. This paper canvasses different approaches that our society has adopted in its response to juvenile offending and explores what factors may increase the risk of juvenile offending and what factors may reduce that risk. The fifth paper by Susan Dennison and Anna Stewart investigates the relationshp between child maltreatment and juvenile offending.

In the sixth and final paper, Ian Nisbet and Katie Siedler examine characteristics of New South Wales adolescent offenders who have been convicted for a range of sex offences. These authors then present a typology of adolescent sex offenders derived from the offending behaviour.

Don Thomson Guest Editor 